
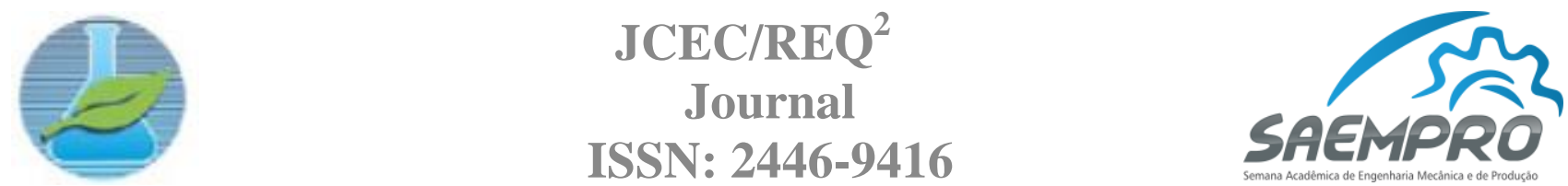

\author{
"EU, A INDÚSTRIA E O MUNDO" \\ 08 a 11 de novembro de 2016 no campus Viçosa da UFV \\ Departamento de Engenharia de Produção e Mecânica - DEP \\ Universidade Federal de Viçosa - UFV
}

\title{
ESTUDO DA ENGENHARIA ORGANIZACIONAL NO PROGRAMA DE EDUCAÇÃO TUTORIAL DA ENGENHARIA DE PRODUÇÃO DA UNIVERSIDADE FEDERAL DE VIÇOSA
}

\author{
Carlos Caiado Abreu França, Gabriel Nunes Fonseca Lima e Silva \\ Universidade Federal de Viçosa, Departamento de Engenharia de Produção e Mecânica \\ $\mathrm{Ph}$. Rolfs s/n - 36570-000 - Viçosa - MG \\ carlos.franca@ufv.br, gabriel.n.silva@ufv.br
}

\section{INTRODUÇÃ̃O}

Vê-se, com a crescente complexidade que as atividades executadas atualmente, a divisão cada vez mais frequente de tarefas e responsabilidades dentro de um grupo. Esta divisão, que de um lado traz aspectos positivos, como viabilizar maior eficiência na realização de tarefas mais complexas, por vezes dificulta a compreensão de quem é responsável por qual atividade, o que é prejudicial à eficiência de equipes. Nesse sentido a descrição de cargos se mostra relevante, de modo a estruturar responsabilidades e áreas de atuação em nesse tipo de realidade. Desta forma, buscou-se estudar o impacto do estudo de cargos dentro de um grupo acadêmico, onde vê-se com frequência a divisão de tarefas, sem, no entanto, uma descrição desses cargos de forma estruturada. Além disso, conforme Chiavenato (2010) afirma, cargos devem ser moldados conforme ocorrem mudanças nas organizações, sendo necessária a descrição e análise dos mesmos. Assim, dentro de um grupo de acadêmicos que buscam potencializar seu trabalho e estruturar suas ações, e com este objetivo, buscou-se realizar este estudo.

\section{CONCEITOS BÁSICOS}

Para a boa compreensão da discussão apresentada aqui, buscou-se definir, com clareza, os conceitos de organograma e descrição de cargos.

Segundo Chiavenato (2001), "organograma é o gráfico que representa estrutura formal da empresa". Dessa forma, entende-se organograma como um diagrama que visa representar as relações de hierarquia entre cargos e/ou setores dentro de uma organização. A representação gráfica organizacional pode ser dada de várias maneiras, sendo as mais difundidas a Funcional e a Horizontal, que representam as hierarquias de forma mais clara e definida. Entretanto, cada vez mais outros tipos de organogramas estão sendo difundidos entre as empresas como o Matricial e o Radial, que conseguem descrever empresas com menores graus de hierarquia.

Descrição de cargos, por sua vez, ainda sob a ótica do mesmo autor, é a análise e definição das atribuições delegadas a um determinado cargo, sendo um retrato simplificado do conteúdo e das principais responsabilidades do cargo de forma a deixar claro suas responsabilidades. Sendo assim, em um documento de descrição de cargos deve ficar claro o que, como, com que frequência e de que forma é feita uma atividade, sendo essa última pouco detalhada.

\section{CARACTERIZAÇÃO DO AMBIENTE}

O Estudo foi realizado no grupo PET da Engenharia de Produção da Universidade Federal de Viçosa. O Programa de Educação Tutorial foi criado um 1979 pelo Governo Federal e é composto 
por grupos de estudantes, com tutoria de um docente, que buscam realizar atividades extracurriculares que complementam sua formação, procurando atender plenamente as necessidades do curso e/ou ampliar e aprofundar nos conteúdos programáticos.

Nesse contexto, Programa de Educação Tutorial da Engenharia de Produção (PET-EPR) possui algumas particularidades. Além da realização de projetos de pesquisa e extensão, seus membros também executam atividades com a finalidade de se desenvolver, assim como desenvolver os discentes do curso de Engenharia de Produção e a sociedade como um todo, atingindo o objetivo principal do Programa. Para isso, no PET-EPR, existe uma estrutura organizacional que divide seus membros nas chamadas coordenadorias, que por sua vez, trabalham para sustentar e apoiar as diversas atividades realizadas e oferecidas ao público externo.

\section{METODOLOGIA}

O trabalho de reconhecimento dos processos e atividades organizacionais foi conduzido pela observação direta das mesmas e através de entrevistas com cada membro do grupo. Portanto, a metodologia utilizada foi a pesquisa ação.

As entrevistas realizadas foram gravadas em áudio para posterior conferência. Elas consistiam de perguntas relacionadas às atividades realizadas por cada integrante da coordenadoria, explicando-as como são feitas e o porquê de serem feitas. Além disso, foram especificadas algumas características comportamentais para que os entrevistados pudessem dar notas de acordo com o grau de necessidade da mesma no cargo que exerce.

\section{RESULTADOS}

O Programa de Educação Tutorial se mostrou um grupo com pouca divisão hierárquica, tendo o professor tutor como a única figura acima de todos os membros, enquanto esses se mantinham no mesmo patamar de hierarquia. A função do tutor é orientar e guiar as diversas atividades promovidas pelo programa. Sendo assim, qualquer membro do PET pode ter contato direto com o mesmo para a realização dessas atividades.

A organização interna do Programa se dá através de coordenadorias, sendo elas a Gestão de Pessoas, Projetos, Gestão por Processos, Comunicação e Estratégica. Os membros se dividem entre elas e dentro das mesmas também não existe hierarquia, uma vez que todos possuem igualdade de responsabilidades e funções. Portanto, considerando essas características, foi escolhido para representação do grupo o organograma circular, que pode ser visto na Fig. 1 abaixo. Esse tipo de organograma representa organizações de menor hierarquia e onde deseja-se ressaltar o trabalho em equipe, apesar do cargo/setor mais ao centro possuir maior nível hierárquico que aqueles nas extremidades.

Como pode ser notado, o organograma do PET não apresenta os cargos, mas sim a organização interna do Programa com relação a seus setores, aqui chamados de coordenadorias. Isso porque, como já dito, os membros de cada uma delas não possuem distinções hierárquicas ou de responsabilidade enquanto integrantes de qualquer uma das mesmas. 


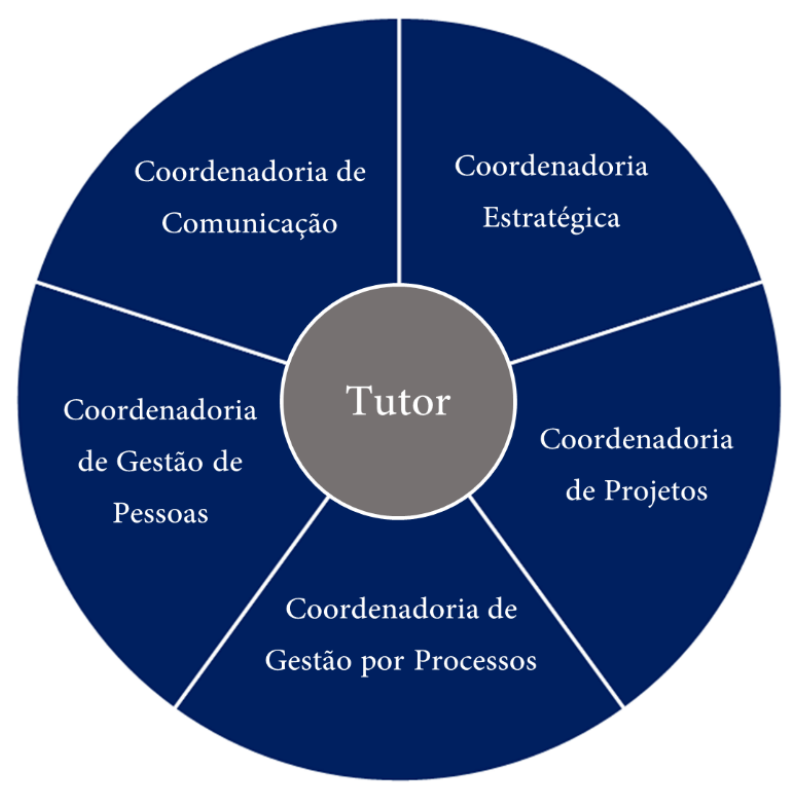

Figura 1 - Organograma do Programa de Educação Tutorial da Engenharia de Produção da UFV.

As descrições de cargo foram feitas de acordo com as atividades de cada coordenadoria. Nas descrições estão contidas a missão de cada coordenadoria, todas as atividades desempenhadas por ela, uma pequena descrição contendo o nome, como e porquê realizá-la e, por fỉm, características comportamentais necessárias para o cargo, acrescida de notas para o caso de maior ou menor intensidade.

\section{CONSIDERAÇÕES FINAIS}

A descrição de cargos se faz necessária a qualquer organização, isso para que o colaborador sabia exatamente o que é esperado dele, além de evitar confusões entre funções que envolvem mais de uma área dentro da empresa. No PET-EPR principalmente, onde o grupo é composto por graduandos com mesma hierarquia e rotatividade é relativamente alta, é imprescindível que se tenha claro funções e deveres de cada um além de registros das mesmas com a finalidade de não se perder conhecimento na troca de membros.

Espera-se que com a descrição de cargos, as atividades para as quais o executor responsável estava duvidoso, agora sejam realizadas pela pessoa designada de forma a manter o programa em funcionamento. Sugere-se um estudo mais aprofundado para avaliar as competências exigidas de cada cargo, sejam elas técnicas ou comportamentais. Isso porque, as notas que as notas que representavam a intensidade da necessidade de cada uma das características comportamentais foram dadas pelos entrevistados, que recorrentemente consideravam todas muito importantes, dando assim, notas elevadas para todas. Conclui-se assim que o estudo foi de relevância para o grupo em que se aplicou, deixando claro a localização de cada membro na estrutura organizacional e suas funções uma vez alocados em sua coordenadoria.

\section{REFERÊNCIAS}

CHIAVENATO, I. “Gestão de pessoas”. 3. ed. rev. atual. Rio de Janeiro: Elsevier, 2010. 579 p.

CHIAVENATO, I. "Teoria Geral da Administração”. Rio de Janeiro: Campus, 2001.

MINISTÉRIO DA EDUCAÇÃO, 2006. "Programa de Educação Tutorial - PET: Manual de Orientações Básicas”. Acesso em; 19 out. 2016. Disponível em: <http://portal.mec.gov.br/pet/manual-de-orientacoes>

SOBRAL, F. PECI, A. “Administração: teoria e prática no contexto brasileiro”. 1.ed. São Paulo: Pearson Prentice Hall, 2008. 